\title{
O PRETÉRITO PERFECTO EM ESPANHOL: ENTRE A EXPRESSÃO DO ANTEPRESENTE E OUTROS VALORES
}

\author{
LEANDRO SILVEIRA DE ARAUJO** \\ (UFU)
}

\begin{abstract}
RESUMO: Este trabalho visa fazer uma análise semasiológica do pretérito perfecto compuesto espanhol (PC - he estudiado). Para tanto, recorre aos postulados teóricos de Reichenbach (2004), Rojo $(1974,1990,1999)$ e Comrie (1976) para descrever os principais valores associados a essa forma verbal pelos estudos descritivos e normativos. Dentre esses valores, destaca-se o de antepresente, que, por isso, recebe especial atenção neste artigo. Contudo, valendo-nos dos referenciais teóricos relativos à temporalidade e aspectualidade, procuramos ainda avaliar outros sentidos também associáveis ao PC. Para evidenciar as descrições realizadas, recorremos a enunciados coletados em gêneros discursivos circulados na esfera jornalística. Como resultado, esperamos poder contribuir um pouco mais para a compreensão do funcionamento dessa forma polissêmica, demonstrando a dinamicidade dessa forma em uso.
\end{abstract}

Palavras-chave: Pretérito perfecto compuesto; Temporalidade; Espanhol.

RESUMEN: Este trabajo hace un análisis semasiológico del pretérito perfecto compuesto (PC - he estudiado) español. Para ello, recurre a los postulados teóricos de Reichenbach (2004), Rojo (1974, 1990, 1999) y Comrie (1976) para describir los principales valores que los estudios descriptivos y normativos atribuyen a dicha forma verbal. Entre esos valores, se sobresale el antepresente, que, por ello, recibe especial atención en este artículo. Sin embargo, valiéndonos de los marcos teóricos relativos a la temporalidad y a la aspectualidad también evaluamos los otros sentidos asociables al PC. Para evidenciar las descripciones realizadas, recurrimos a enunciados recogidos de géneros discursivos difundidos por la esfera periodística. Como resultado, esperamos poder contribuir un poco más para la comprensión del funcionamiento de esa forma polisémica, enseñando lo dinámico de esa forma en uso. Palabras clave: Pretérito perfecto compuesto; Temporalidad; Español.

* Devo aos pareceres emitidos a este trabalho meu agradecimento pelas leituras cuidadosas e sugestões generosas que permitiram o refinamento do texto publicado. Assumo, contudo, qualquer possível equívoco que ainda tenha escapado às muitas releituras do texto.

**araujols@ufu.br 


\section{INTRODUÇ̃̃O}

Encontramos em Andrés Bello (1972, 2004), ${ }^{1}$ gramático cofundador da tradição moderna descritiva do castelhano, uma proposta de categorização do passado na língua em cinco âmbitos temporais: (i) o pretérito, (ii) o copretérito, (iii) o antepresente, (iv) o antepretérito e o (v) antecopretérito, para os quais correspondem, respectivamente, as cinco formas de passado que se encontram disponíveis no sistema espanhol: amé, amaba, he amado, hube amado e había amado. ${ }^{2}$

No primeiro âmbito encontra-se o pretérito ou passado absoluto, que "significa a anterioridade do atributo ao ato da palavra" (BELLO, 1972, p. 7). Conforme a característica aspectual da base verbal, observa-se uma situação que chega à sua perfeição e expira, isto é, "a anterioridade de toda a duração do atributo ao ato da palavra", ou que subsiste durando - ou seja, "a anterioridade apenas daquele instante em que o atributo chega a sua perfeição" (BELLO, 2004, p. 200). Para o autor, encontramos o primeiro comportamento em verbos desinentes (télicos), e o segundo, em verbos permanentes (atélicos), como os enunciados (1) e (2) mostram.

(1) 29 de enero. María Jesús Rufas, de 74 años, murió asesinada en su chalé de Calviá. ${ }^{3}$ 29 de janeiro. María Jesús Rufas, de 74 anos, morreu assassinada em seu chalé de Calviá.

(2) La fuerte explosión se oyó en toda la ciudad, y los residentes salieron a los balcones. ${ }^{4}$ Ouviu-se a forte explosão em toda a cidade, e os moradores saíram às sacadas".

O copretérito, por sua vez, refere-se à coexistência do atributo a um fato passado, de maneira que "a duração do fato passado com que é comparado forma apenas uma parte da sua" duração (BELLO, 1972, p. 8). Por exemplo, em (3), a chuva (lluvia) coexiste, por um instante, com a chegada do socorro (recogieron):

(3) Cuando nos recogieron, llovía con una inclemencia extraordinaria [....$^{5}$

Quando nos pegaram, chovia com uma severidade extraordinária.

O terceiro âmbito temporal, o de antepresente, envolve situações passadas que mantêm relação com algo que ainda existe. Esse é o caso de (4), em que a precipitação (ha precipitado) ocorre em um contexto temporal ainda existente (hoy) no ato de enunciação:

(4) [...] ni hoy se ha precipitado irremediablemente en el infierno de una crisis. ${ }^{6}$

[...] nem hoje se precipitou irremediavelmente no inferno de uma crise.

\footnotetext{
${ }^{2}$ As primeiras publicações das obras de Bello (1972, 2004) datam, respectivamente, de 1841 e 1847.

${ }^{3} \mathrm{Na}$ nomenclatura tradicional, os valores correspondem respectivamente aos pretéritos perfecto simple, imperfecto, perfecto compuesto, anterior, pluscuamperfecto.

${ }^{4}$ Enunciado retirado da versão eletrônica do jornal espanhol El País, de 28/12/2011.

${ }^{5}$ Enunciado retirado da versão eletrônica do jornal argentino La Nación, de 18/02/2016.

${ }^{6}$ Enunciado retirado da versão eletrônica do jornal argentino La Nación, de 24/03/2014.
} 
O quarto âmbito, por sua vez, refere-se ao antepretérito e, como tal, "significa que o atributo é imediatamente anterior a outra situação, que tem relação de anterioridade com o momento em que falo" (BELLO, 2004, p. 203). Desse modo, o enunciado (5) mostra-nos que o amanhecer (hubo amanecido) é imediatamente anterior ao "sair" (sali), que, por sua vez, é uma ação passada em relação à fala. Apesar de reconhecermos que a descrição do sistema temporal feita por Andrés Bello $(1972,2004)$ data de mais de 160 anos, é importante salientar que os estudos mais contemporâneos (CARTAGENA, 1999; RAE, 2009, 2010) apontam o desuso dessa forma composta na oralidade, permanecendo restrita ao registro formal escrito.

(5) Cuando hubo amanecido, salí. (Bello, 2004, p. 203)

Assim que amanheceu, sai.

Por último, o âmbito do antecopretérito abriga o atributo que é anterior a uma situação que, por sua vez, é anterior ao momento em que se enuncia. Esse é o caso de (6), em que a intenção (había anticipado) é anterior à morte do animal (mató). Diferentemente do valor de antepretérito, observamos que no antecopretérito não se indica que a sucessão entre as duas situações descritas é imediata, mas que provavelmente envolve um intervalo relativamente maior.

(6) También mató al perro a machetazos, como había anticipado en su cuaderno escolar. ${ }^{7}$

Também matou o cachorro à facada, como havia antecipado em seu caderno da escola.

Finalmente, ressaltamos que essa simples apresentação sobre a expressão do passado em espanhol não visa a uma descrição sistemática e minuciosa do funcionamento das formas verbais próprias do pretérito, mas a uma modesta apresentação da macroenvoltura temporal em que se alinha o pretérito perfecto compuesto (PC). Contudo, a fim de dirigirmos especificamente aos propósitos deste estudo, isto é, identificar e descrever as possibilidades expressivas dessa forma essencialmente polissêmica na língua espanhola, procederemos, nos próximos parágrafos, à descrição do funcionamento do perfecto compuesto partindo da revisão das principais gramáticas da língua espanhola. Para tanto, nossa discussão parte do quadro 1 , em que sintetizamos os sentidos que cada um dos manuais atribui ao PC. Em um primeiro momento, nossa análise voltase ao valor mais comumente associado ao PC, ou seja, o antepresente e suas especificações (ampliado e imediato). Em seguida, ampliamos a discussão para proceder à análise de outros valores que, com menor recorrência, também são atribuídos ao PC (relevância presente, resultado, continuidade, passado absoluto, antepretérito, prospectivo). Como veremos, esse último grupo caracteriza-se por uma marcação mais aspectual dos sentidos expressos.

Alertamos que, ao longo da discussão, recorreremos a enunciados coletados de gêneros discursivos da esfera jornalística com o propósito de mostrar como se constrói no uso efetivo da língua os valores associados ao PC.

\footnotetext{
${ }^{7}$ Enunciado retirado da versão eletrônica do jornal espanhol El País, de 26/04/2016.
} 


\begin{tabular}{|c|c|c|c|c|c|c|c|c|c|c|}
\hline \multirow{17}{*}{ 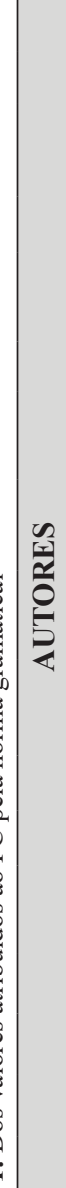 } & RAE $(2009,2010)$ & + & + & + & + & + & + & + & I & + \\
\hline & TORREGO (2002) & + & ' & ' & + & + & ' & + & ' & + \\
\hline & $\begin{array}{l}\text { QUESADA PACHECO } \\
\text { (2001) }\end{array}$ & + & + & + & + & + & + & ' & ' & I \\
\hline & CARTAGENA (1999) & + & 1 & 1 & + & + & + & + & + & + \\
\hline & $\begin{array}{c}\text { GUTIÉRREZ ARAUS } \\
(1995,2001)\end{array}$ & + & 1 & 1 & + & + & + & + & ' & ' \\
\hline & KOVACCI (1992) & ' & + & 1 & ' & ' & + & 1 & 1 & ' \\
\hline & $\begin{array}{c}\text { PORTO DAPENA } \\
(1989)\end{array}$ & + & + & + & ' & + & + & 1 & ' & + \\
\hline & $\begin{array}{c}\text { HERNÁNDEZ ALONSO } \\
(1996)^{13}\end{array}$ & + & ' & ' & + & ' & ' & ' & ' & 1 \\
\hline & $\begin{array}{l}\text { ALARCOS LLORACH } \\
(1980,2005)^{12}\end{array}$ & + & + & + & + & + & + & 1 & ' & I \\
\hline & $\begin{array}{c}\text { ROJO } \\
(1974,1990,1999)\end{array}$ & + & ' & 1 & + & + & ' & + & ' & + \\
\hline & RAE (1986) ${ }^{11}$ & + & + & ' & + & + & 1 & + & 1 & \\
\hline & GILI GAYA (1979) & + & + & + & + & + & + & 1 & 1 & 1 \\
\hline & $\begin{array}{c}\text { GARCÍA DE DIEGO } \\
(1951)\end{array}$ & + & + & + & + & + & + & 1 & ' & 1 \\
\hline & KANY (1970) ${ }^{10}$ & + & + & 1 & + & + & ' & + & ' & ' \\
\hline & LENZ (1920) & I & 1 & 1 & + & + & ' & + & 1 & 1 \\
\hline & $\operatorname{BELLO}(1972,1999)^{9}$ & + & + & + & + & + & + & ' & ' & + \\
\hline & NEBRIJA $(1980)^{8}$ & + & ' & ' & ' & ' & I & ' & ' & 1 \\
\hline & \multirow[t]{2}{*}{ 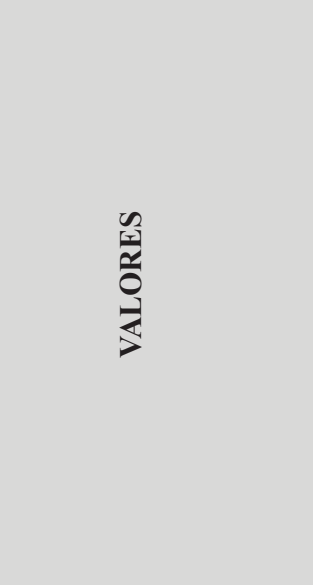 } & 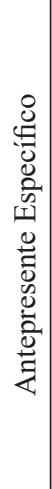 & 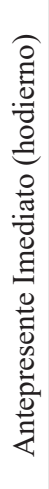 & 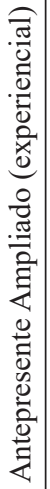 & 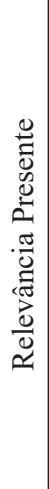 & 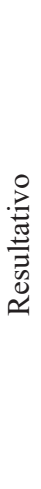 & 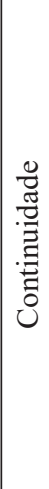 & 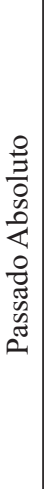 & 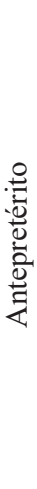 & 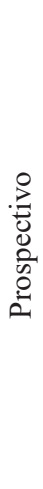 \\
\hline & & - & $\sim$ & $m$ & $\nabla$ & in & 6 & N & $\infty$ & $a$ \\
\hline
\end{tabular}

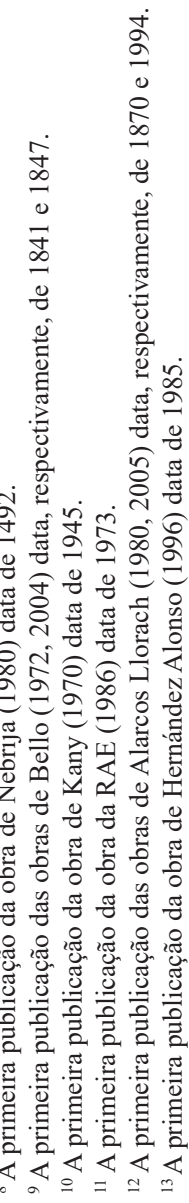


Tendo em vista a apresentação pobre e impressionista que fazem esses manuais, a abordagem semasiológica que fazemos aqui se consolidará ao ampliar a discussão sobre os valores atribuídos ao PC, recorrendo a importantes postulados teóricos sobre aspectualidade (COMRIE, 1976) e temporalidade verbal (REICHENBACH, 2004; ROJO, 1974, 1990, 1999). Conforme já conferimos, o quadro 1 explicita como a norma gramatical vem descrevendo o comportamento do perfecto compuesto. Assim, se com a soma de todas as descrições é possível identificar um uso marcadamente polissêmico da forma composta (9 sentidos), com a análise individualizada de cada um desses manuais, por outro lado, observamos a ausência de uma descrição sistemática que considere a totalidade de possibilidades de uso do PC.

Conforme também explicita o quadro 1, o antepresente - concepção temporal um tanto ambígua e de definição pouco acertada entre as gramáticas - é o sentido mais referido por esses manuais, de tal modo que lhe dedicamos maior atenção neste estudo. Assim, o antepresente será tomado neste trabalho não apenas como a nomenclatura atribuída à forma composta por Andrés Bello (1972, 2004), mas como como o sentido mais recorrentemente associado ao PC.

\section{O PERFECTO COMPUESTO E O ANTEPRESENTE}

Nesta seção discutiremos em que consiste o valor geral de antepresente (AP) e como outros dois sentidos (ampliado e imediato) podem ser atribuídos ao PC a partir da concepção geral do AP. A fim de compreender a aproximação entre o PC e o AP, partimos do estudo morfossemântico dessa forma, segundo o qual se observa que ao auxiliar haber corresponde a informação de anterioridade ao tempus no qual está conjugado - anterioridade ao presente do indicativo (ALARCOS LLORACH, 2005). Além disso, é lhe atribuída também a marcação da informação gramatical de pessoa, número, aspecto e modo, haja vista que é nele que se acoplam os sufixos de número/pessoa e tempus ${ }^{14} /$ aspecto/modo. Por sua vez, ao particípio - portador do valor léxico - cabe a observação da situação passada e perfectiva, bem como a determinação de uma rede argumental; condicionando, por isso, sujeitos e complementos associáveis à construção (RAE, 2009, p. 184). São essas características que possibilitam considerar o PC como "uma forma do passado que se projeta em direção ao presente" (HERNÁNDEZ ALONSO, 1996, p. 449).

\footnotetext{
${ }^{14}$ Santos (1974) observa em algumas línguas a diferenciação lexical entre o conceito de tempo não linguístico (cronológico, físico e psicológico) - e a expressão do tempo linguístico por meios gramaticais. Reproduzindo essa distinção, usaremos, respectivamente, tempo e a forma latina tempus (com o plural tempora).
} 
Cartagena (1999), por seu turno, inicia o estudo do PC comparando-o com o tempus das formas simples, pois, para o autor, essas formas possuem a função de delinear, a partir do ponto zero, segmentos temporais primários. ${ }^{15} \mathrm{Na}$ mesma direção, os compostos por haber+particípio formam fragmentos temporais secundários de perspectiva retrospectiva em cada um dos âmbitos primários. Em outros termos, por serem relativas, isto é, não guardarem relação direta com o momento de enunciação, mas com as formas simples, as formas compostas ressegmentam cada parte já dividida primariamente pelos tempora simples. Assim, "[...] He hecho, hube hecho, habré hecho indicam anterioridade, mas em relação ao ponto central de cada âmbito temporal gerado pelas formas simples, apareça este, ou não, expressamente referido nos textos".

Diante da síntese de funcionamento do sistema verbal da língua espanhola, conseguimos verificar como se instaura o antepresente na forma do PC: um valor relativo de anterioridade (em um âmbito secundário) ao tempus presente que lhe serve de referência dentro do âmbito primário. Reparemos que tanto a expressão de anterioridade quanto a referência no presente estão contidas no "âmbito primário de coexistência" ao momento de fala (MF). Esse valor é apreciado na figura 1, em que se expõe parte das formas verbais do indicativo (CARTAGENA, 1999, p. 2938). Em destaque, o PC representa a expressão de uma anterioridade (no âmbito secundário), que está contida no "âmbito primário de coexistência" (APco).

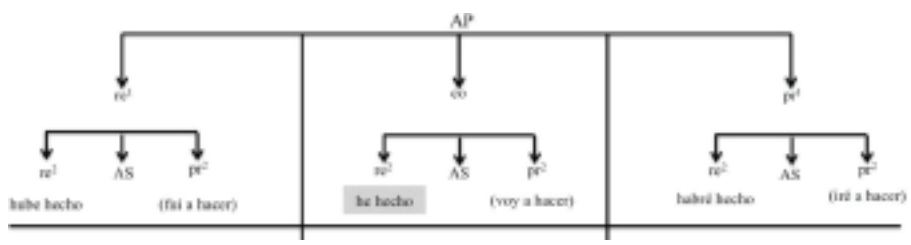

Figura 1: Do tempus nas formas verbais do indicativo ${ }^{16}$

Fonte: Cartagena (1999, p. 2938) - Adaptação nossa.

Desse modo, diferentemente do perfecto simple (hice), canonicamente responsável pela expressão de situações pretéritas envolvidas por um "âmbito primário de anterioridade", com o perfecto compuesto (he hecho), apresenta-se um evento passado envolvido por uma percepção de presente ("âmbito primário de coexistência”) e que, por isso, guarda uma relação temporal de coexistência com o MF (antepresente). A fim de delinearmos esse âmbito temporal e respeitando às dimensões que ele pode receber na língua espanhola, passemos a observação de sua categorização e seu potencial de ajuste em três subdivisões: imediato, específico e ampliado.

${ }^{15}$ Isso é assim porque as formas simples expressam tempora absolutos, que, como tal, guardam relação direta com o momento de enunciação.

${ }^{16} \mathrm{Na}$ figura 1, AP quer dizer Âmbito Primário; AS, Âmbito Secundário e RE, CO e PR, respectivamente, REtrospectividade, COexistência e PRospectividade. 


\subsection{O antepresente específico}

Mesmo se tratando de um valor passado, Reichenbach (2004) insere o AP no âmbito referencial concomitante (R Presente) ao momento de fala (MF), sem eliminar, é claro, seu traço de anterioridade. Como ilustra a figura 2, a relação de anterioridade da situação descrita (ME) estabelece-se dentro da perspectiva referencial de presente (R Presente), o que, na notação de Reichenbach (2004), representa-se por ME-MR,MF, isto é, um evento (ME) passado assistido a partir de uma referência (MR) concomitante ao momento de fala (MF). Assim, ao dizer (7), o enunciador insere a ação passada ( $\mathrm{ME}$ - han dicho) dentro de um âmbito referencial (MR - esta mañana) que persiste ao produzir o enunciado (MF).

(7) En esta mañana se han dicho dos cosas eh ... yo creo que es interesante ¿no? ${ }^{17}$

Duas coisas foram ditas nesta manhã eh... Eu acho que é muito interessante ¿não?

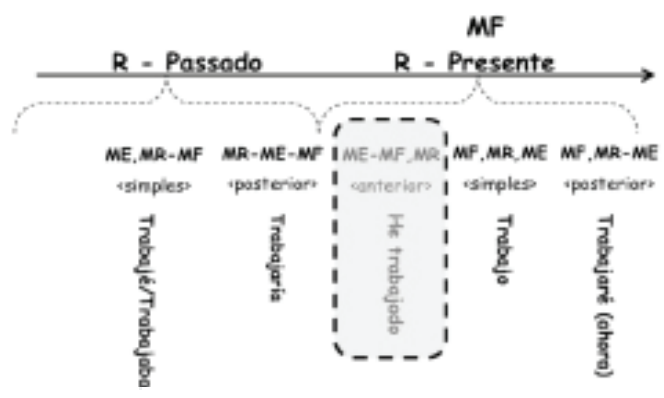

Figura 2: Da categorização do antepresente na língua segundo Reichenbach

Na mesma direção, Rojo (1974, 1990, 1999) considera o valor de antepresente detentor de uma estruturação relativa, pois a informação temporal de anterioridade (-V) que promulga estabelece-se tomando como referência outro valor temporal: o próprio presente $(0 \mathrm{oV})$. Assim, para o autor, o AP expressa um acontecimento anterior a uma referência $(0 \mathrm{oV})$ que, por sua vez, é simultânea à origem. ${ }^{18}$ De modo prático, observamos em (7) "esta mañana” estabelecendo-se como referência concomitante ao ponto zero, isto é, à enunciação, e a partir da qual se estabelecerá a base temporal para construção do valor de anterioridade relativa própria do $\mathbf{A P}$.

17 Enunciado retirado de uma entrevista radiofônica difundida pela rádio COPE, de Madri/ Espanha (10/09/2013).

${ }^{18}$ Rojo $(1974,1990,1999)$ nomeia a referência fundamental do tempus de ponto central ou ponto zero $(0)$, isto é, a origem com relação à qual se orientam de forma mediata ou imediata as situações. A partir do ponto zero, verifica-se a possibilidade de orientarmos os eventos como anteriores $(-\mathrm{V})$, simultâneos $(\mathrm{oV})$ ou posteriores $(+\mathrm{V})$. 


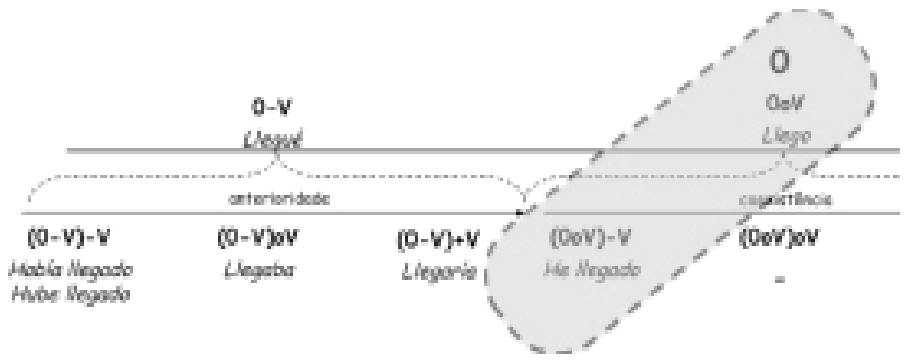

Figura 3: Da expressão do antepresente no espanhol segundo Guillermo Rojo

Conforme ilustra a figura 3 , diferente do valor de passado absoluto (V-O - llegué), que também corresponde a uma ação pretérita, no entanto assistida a partir de um "âmbito primário de anterioridade" (MR-pretérito), com o antepresente $((0 \mathrm{oV})-\mathrm{V}-$ he llegado), é apresentado um evento pretérito envolvido por uma percepção de presente (MR-presente/âmbito primário de coexistência), que, por isso, guarda uma relação temporal de coexistência com o MF, ou seja, de AP. Segundo Cartagena (1999), esse valor indica:

[...] que una acción se realiza antes del punto cero que nos sirve de referencia para medir el tiempo, pero dentro del ámbito que tiene como centro la coexistencia o simultaneidad del dicho punto con el momento del habla (CARTAGENA, 1999, p. 2941). ${ }^{19}$

Resulta-nos ainda dificultoso compreender o que, para o falante, pode ser considerado suficientemente relevante e/ou próximo ao momento de enunciação a ponto de ser envolvido pelo mesmo âmbito primário de coexistência/MR-Presente. A fim de melhor entender a possível extensão do distanciamento existente entre o ME e o MF no valor de AP, muitos valem-se da observação de elementos linguísticos recorrentes no contexto de uso das formas.

Assim, observando alguns marcadores que possuem características temporais que se assemelham ao valor em análise, encontraríamos o antepresente ocorrendo "com os advérbios que indicam que a ação se deu em um período de tempo no qual se encontra compreendido o momento presente do que fala ou escreve", tal seria o caso de "hoy, ahora, estos días, esta semana, esta tarde, esta mañana, este mes, el año en curso, esta temporada, hogaño, todavía no, en mi vida, durante el siglo presente, etc" (ALARCOS LLORACH, 1980, p. 24). Apesar da grande diferença na amplitude temporal abarcada por cada um desses marcadores, observemos que com qualquer uma dessas expressões conseguimos envolver em um mesmo âmbito temporal (MR) tanto a situação descrita (ME) como o momento de fala (MF). Ou seja, ao dizermos:

$19<$ Tradução nossa> "[...] que uma ação se realiza antes de um ponto zero que nos serve de referência para medir o tempo, mas dentro do âmbito que tem como centro a coexistência ou a simultaneidade de tal ponto com o momento de fala" (CARTAGENA, 1999, p. 2941). 
(8a) La ópera prima del director indio ha ganado hoy la Butaca de oro [... ${ }^{20}$

A ópera prima do diretor indiano ganhou hoje a Butaca de oro [...].

(8b) La ópera prima del director indio ha ganado este año la Butaca de oro.

A ópera prima do diretor indiano ganhou este ano a Butaca de oro.

consideramos que tanto o acontecimento ('ha ganado') como o MF compartilham da mesma envoltura temporal: "hoy" (hoje) ou "este año" (este ano), respectivamente. Além disso, nas orações de (8), a recorrência do valor de antepresente mostra-nos que não parece ser fundamental que a distância existente entre a situação (ME) e o ato de enunciação (MF) seja igual ou menor que um dia, mas que é suficiente haver uma relação temporal imbricada entre elas.

Tanto é assim que, de acordo com a "Nueva gramática de la lengua española" (RAE, 2009, p. 1722 e 1723), o valor de antepresente coincide temporalmente, entre outros, com:

i. O demostrativo este: "En este siglo la ciencia ha experimentado grandes avances". Em oposição ao demonstrativo aquel, que indicaria um âmbito primário de anterioridade e, por isso, associado ao valor de passado absoluto: "En aquel siglo la ciência experimentó grandes avances".

ii. O Adjetivo actual: "En su actual situación laboral, ha sufrido no pocos sinsabores". Em oposição ao adjetivo anterior, que indicaria um âmbito primário de anterioridade e, por isso, associado ao valor de passado absoluto.

iii. O Adjetivo presente: "La vicetiple ha tenido días mejores en la presente temporada".

Em acréscimo, Alarcos Llorach (1980) afirma que mesmo em enunciados de sentido antepresente sem uso de marcadores temporais pode-se observar implicitamente a consciência do falante de que os eventos têm como limite o presente gramatical. Nesses casos, infere-se o especificador "neste período de tempo em que falamos". A observação da expressão do antepresente específico aliada à revisão bibliográfica relacionada ao tema despertou-nos a percepção de dois outros subâmbitos temporais resultantes do desdobramento perceptível do momento de referência: o de AP imediato e o de AP ampliado, os quais descreveremos nas linhas seguintes.

\section{2. $O$ antepresente imediato}

Encontramos nesse subvalor de AP as mesmas características já examinadas, de modo geral, no valor de AP específico, no entanto, acresce-se a seu campo semântico a especificidade de um traço imediato, ou seja, o momento de referência (MR) que envolve tanto a situação descrita (ME) como o ato de enunciação (MF) passa a ser mais limitado, obrigando, por conseguinte, que dada situação esteja mais próxima ao momento de fala. Tal uso poderia ser verificado em:

\footnotetext{
${ }^{20}$ Enunciado retirado da versão eletrônica do jornal espanhol El País, de 29/11/2014.
} 
(9) [...] algo que ha sorprendido en las últimas horas tiene que ver con el crecimiento de algunos proyectos que vienen desde China directamente. ${ }^{21}$

[...] algo que surpreendeu nas últimas horas tem a ver com o crescimento de alguns projetos que vêm diretamente da china.

Enunciado que nos mostra, graças ao uso do marcador temporal "en las últimas horas", que a situação descrita ("ha sorprendido") terminou muito recentemente. No entanto, notamos que a maioria dos estudos segue permeada por uma dificuldade em delimitar a dimensão da "referência temporal de coexistência" nesse valor, marcado por uma traço de maior instantaneidade. Na tentativa de dar fim à falta de precisão, alguns pesquisadores chamam esse valor de hodierno, ${ }^{22}$ indicando que a delimitação da distância existente entre o momento da fala e o momento do evento insere-se nos limites de um dia. Advertimos, no entanto, que essa especificação nem sempre é segura, haja vista que pode sofrer alterações conforme a percepção temporal do falante. Esse é o caso de:

(10a) No ha venido esta mañana.

Não veio esta manhã

(10b) No vino esta mañana.

Não veio esta manhã

Segundo Alarcos Llorach (2005, p. 167), a diferença dessas orações reside na possibilidade de se considerar, "esta mañana", em (10a), como parte de "hoje", portanto, dentro do "âmbito primário de coexistência" do contexto hodierno. E, por outro lado, em (10b), considerar "esta mañana" como oposto a "esta tarde", quando provavelmente se enuncia. Assim, a situação descrita seria colocada fora do "âmbito de coexistência", cuja abrangência envolveria apenas o período vespertino do dia. Em síntese, parece que a distinção, marcada pelo uso de uma forma ou outra, resulta das diferentes percepções de tempus que se têm do evento. Esse tratamento estrito dos limites de uso das formas do perfecto pressupõe uma correlação biunívoca entre forma e função.

Finalmente, ressaltamos que a diferença existente entre o valor de AP específico e o imediato (hodierno) reside fundamentalmente na extensão do "âmbito primário de coexistência" (MR). Por isso, parece-nos apropriado tratar o segundo sentido como uma delimitação do valor de AP específico, cujo âmbito de coexistência pode se estender mais livremente e, consequentemente, envolver situações mais distantes do MF. Por fim, assinalamos que os dois valores podem ser observados na figura 4, em que o colchete menor representa uma menor abrangência do "âmbito de coexistência" (MR presente) e, consequentemente, a maior proximidade que há entre o momento do evento (ME) e o momento de fala (MF) no valor hodierno. Já o

${ }^{21}$ Enunciado retirado de uma entrevista radiofônica difundida pela rádio LV10, de Mendoza/ Argentina (13/08/2010).

${ }^{22}$ Do latim, hodiernus, que quer dizer "do dia de hoje" (RAE, 2009, p. 1730). 
colchete maior de MR-presente, tracejado, mostra-nos a maior extensão do "âmbito de coexistência", facultando, por isso, um maior distanciamento entre o ME e o MF, tal como ocorre no AP específico.

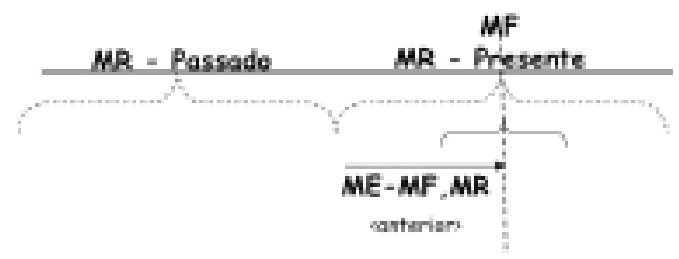

Figura 4: Dos valores de antepresente específico e antepresente imediato (hodierno)

\subsection{O antepresente ampliado}

Identificado pela norma gramatical como experiencial, o valor aqui denominado AP ampliado indica-nos que uma situação manteve-se, pelo menos uma vez, durante algum tempo anterior ao momento de fala, abrangente e muito pouco especificado. De modo que podemos lhe atribuir uma indeterminação temporal, já que não especifica, na linha do tempo, exatamente o momento quando dado evento sucedeu. Isso é o que ocorre em

(11) [...] vamos a hablar ya mismo, precisamente, con Jorge Valentín que ha hecho esa y otras declaraciones para esta nota de la voz del interior. ${ }^{23}$

[...] vamos falar agora mesmo, precisamente, com Jorge Valentín, que fez essa e outras declarações pra esta nota da voz do interior.

Apesar de não especificar quantas vezes, por quanto tempo ou em que momento exato Jorge Valentín fez suas declarações, o exemplo faz-nos saber que o entrevistado esteve em contato com o jornal 'la voz del interior' por mais de uma ocasião num passado não determinado exatamente, mas que é envolto pelo mesmo "âmbito primário de referência presente" (MR) que abrange o MF. Devemos observar, ainda, que ao dizer "esta nota", delimita-se, de alguma maneira, o âmbito temporal primário no qual a situação descrita ocorreu. Ou seja, essa quantidade de interações com o entrevistado ocorreu durante o tempo que envolveu a preparação da edição do jornal. Assim, se por um lado a ausência de um delimitador temporal explícito faz-nos considerar que o evento pode ter ocorrido uma ou mais vezes no período que aparentemente envolve grande parte da vida do observador (RAE, 2009), por outro, com o uso de um especificador ("esta nota"), o momento em que o evento ocorreu é diminuído, sem, contudo, determinar exatamente quando se deu a situação.

${ }^{23}$ Enunciado retirado de uma entrevista radiofônica difundida pela rádio Cadena 3, de Córdoba/Argentina (13/06/2010). 
Há de se considerar que a ausência de um delimitador temporal explícito pode favorecer uma interpretação mais ampla do âmbito temporal em que dado evento aconteceu. De maneira que o enunciador e/ou o enunciatário pode considerar que a situação descrita tenha sucedido em qualquer momento durante um extenso período, que não raramente pode envolver até mesmo toda a existência do experimentador. Assim, o enunciado (12) - mesmo trazendo explicitamente um especificador temporal ("en mi larga carrera") - ilustra-nos como o "âmbito primário de referência” (MR presente) se arrasta a ponto de envolver um longo período da existência do enunciador. Notemos ainda que é a ampliação do momento de referência que permite estabelecer uma relação entre a situação descrita e o MF, facultando, de alguma maneira, a leitura de AP.

(12) [...] en mi larga carrera de actor he dirigido espectáculos musicales, como los del Carmen Flores. ${ }^{24}$

[...] em minha longa carreira de ator dirigi espetáculos musicais, como os de Carmen Flores.

O ampliado pode ser observado na figura 5, na qual as letras (x) tracejadas mostram-nos o desconhecimento da quantidade de vezes que ocorre o evento descrito. Por sua vez, a linha temporal tracejada acusa-nos a indefinição do momento exato em que se deu a situação. Podemos observar, contudo, que, apesar da imprecisão, a situação continua sendo tratada dentro do "âmbito primário de coexistência" (MR-Presente), já que o falante pode estendê-lo a ponto de envolver toda sua vida.

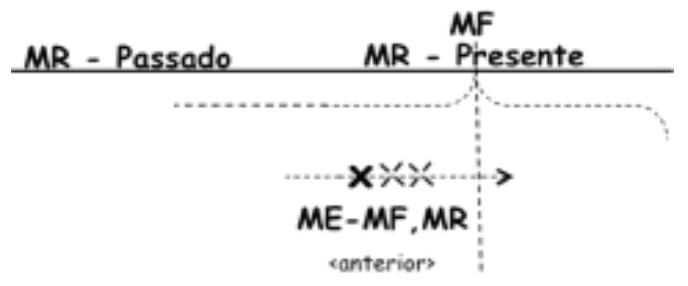

Figura 5: Do valor antepresente ampliado

A RAE (2010, p.429) afirma que "últimamente, en estos tiempos, en estos dias, as fórmulas a lo largo de + grupo nominal quantitativo temporal, en \{más $\sim$ menos\} $d e+$ grupo nominal quantitativo temporal ou $\{$ desde $\sim$ hasta $\}+$ advérbio ou grupo nominal de sentido temporal" são exemplos de expressões temporais do espanhol que corroboram o valor de AP ampliado. Há ainda outros marcadores temporais que não delimitam o âmbito temporal em que uma situação ocorre, mas salientam o sentido prototípico de indeterminação temporal associado a esse uso. Esse é o caso dos advérbios 'nunca' e 'siempre' (que consideram toda a vida do indivíduo) e das locuções 'alguna vez' e 'en alguna ocasión'(as quais se relacionam à quantidade de ocorrências do evento).

${ }^{24}$ Enunciado retirado de uma entrevista radiofônica difundida pela rádio Palermo, de Buenos Aires/Argentina (29/09/2010). 
A indeterminação do momento passado em que se deu o evento pode estar também associada a perguntas e à negação, tal como verificamos em (13) e (14), respectivamente:

(13) ¿Qué cosas te han hecho o has hecho cuando tenías desconfianza [...]??25

Que coisas te fizeram ou você fez quando tinha desconfiança?

(14) Hasta el fondo mismo, hasta donde no ha llegado absolutamente nadie.

Até o fundo do mar, até onde não chegou absolutamente ninguém.

Outras duas características são acrescidas ao valor ampliado por Rodriguez Louro (2008). Para a autora, com esse sentido, o verbo conjugado no PC pode ser parafraseado por "ha tenido la experiencia de", de modo que (15) pode ser interpretado como (16):

(15) De verdad, yo no puedo decir ninguno del interior porque Rosario, Newells y Colón han estado en copa de libertadores. ${ }^{26}$

Na verdade, eu não posso dizer nenhum do interior porque Rosario, Newells e Colón estiveram na copa libertadores.

(16) De verdad, yo no puedo decir ninguno del interior porque Rosario, Newells y Colón han tenido la experiencia de estar en copa de libertadores.

$\mathrm{Na}$ verdade, eu não posso dizer nenhum do interior porque Rosario, Newells e Colón tiveram a experiência de estar na copa libertadores.

Atendo-se ao sujeito que se associa ao PC com valor ampliado ou experiencial, Rodriguez Louro (2008) verifica a recorrência desse argumento com traço animado; de modo que, no enunciado (15), podemos pensar que ao citar o nome dos times, considera-se, metonimicamente, o grupo de pessoas que compõe cada um dos clubes - jogadores, treinador, administração, etc.

Por fim, reafirmamos que entendemos o valor ampliado como um desdobramento do valor de AP específico porque, como vimos, mantém a relação existente entre o MF e a situação descrita (ME) graças à ampliação do "âmbito primário de coexistência". Assim, o momento de referência (MR-Presente) continua apresentando as mesmas características que apresenta nos valores de AP específico e imediato - o que garante uma apreciação parecida do passado.

\footnotetext{
${ }^{25}$ Enunciado retirado de uma entrevista radiofônica difundida pela rádio LV12, de San Miguel de Tucumán/Argentina (21/06/2010).

${ }^{26}$ Enunciados (14) e (15) retirados de uma entrevista radiofônica difundidas pela rádio LV10, de Mendoza/Argentina (13/09/2010).
} 
De modo sintético, o estudo do valor de antepresente revela que suas três nuances correspondem à sistematização de diferentes amplitudes temporais, as quais, a despeito de suas particularidades, têm em comum a retratação de uma situação pretérita (ME) que ocorre em um âmbito temporal (MR) ainda vigente no momento de fala (MF). Isso posto, não raramente, o falante pode intervir na descrição dos fatos que apresenta, inserindo os acontecimentos narrados dentro de uma concepção temporal que, para o enunciador, ainda se encontra em vigor - especialmente quando se trata do antepresente ampliado. Essa possibilidade de intervenção fica ainda mais evidente quando se estudam outros valores atribuídos ao PC, como pontuaremos a seguir.

\section{O PERFECTO COMPUESTO E OUTROS VALORES}

Conforme já pontuamos, apesar da tendência aparentemente mais comum da norma gramatical em atribuir ao PC o valor de antepresente, identificamos ainda outros valores se associando a essa forma verbal: relevância presente, resultado, continuidade, passado absoluto, antepretérito e prospectivo, os quais exploraremos nessa seção.

\subsection{Relevância presente}

Conforme explicam Sperber e Wilson (1994, 1995), os seres humanos, naturalmente, detêm-se com mais atenção em alguns fenômenos em detrimento de outros, de maneira que essa percepção pode ser instaurada e processada na língua de diferentes maneiras. Essas intuições não são muito fáceis de serem deduzidas ou evidenciadas. Contudo, para uma suposição ser considerada relevante em um contexto, ela deverá trazer necessariamente algum efeito para o contexto instaurado.

Aplicando essa premissa ao estudo do PC, Bybee e Dahl (1989, p. 67) definem que, semanticamente, a característica mais importante do perfect - forma verbal equiparável ao perfecto compuesto - é apresentar a situação descrita como relevante para um momento posterior ao tempo em que ocorre - normalmente, para o momento de fala. Em outros termos, por meio do PC mostra-se, no presente, os o efeitos de uma situação cuja origem é anterior ao MF. É bem verdade que se afirma que tanto a origem como o fim da situação já ocorreram quando enunciados; no entanto, nem sempre o término dos acontecimentos está claramente marcado antes do momento de enunciação.

Dahl e Hedin (2000) consideram que os verbos que exprimem um resultado inerente (télicos e pontuais) são mais favoráveis a uma leitura de relevância presente, posto que esses verbos carregam consigo um estado resultante do seu término. Assim, os verbos "morrer" e "partir", por exemplo, implicam automaticamente um estado de "perda de vida" e "ausência", respectivamente. Por seu turno, Rodriguez Louro (2008) defende que o valor de relevância presente decorre de efeitos que vão além das marcações lexicais e gramaticais de temporalidade, pois também 
corresponde a "uma relação um tanto subjetiva e pragmática que une, de acordo com a postura do locutor, uma eventualidade e o momento de fala" (RODRIGUEZ LOURO, 2008, p. 3). Por isso seu uso é caracterizado como portador de uma acepção bastante individualizada e de difícil definição.

Tendo em vista a complexidade dessa relação, a utilização do PC, no enunciado (17), ilustra-nos como um evento passado estabelece uma relação de relevância no $\mathrm{MF}$ :

(17) Si bien le costó [a Vélez Sarsfield] y mucho ganarle a Argentino Junior; Pero también, junto con River, ha ganado sus tres partidos y de esta manera es uno de los punteros que tiene el campeonato apertura de primera división. ${ }^{27}$

Apesar de ter custado muito ao Vélez Sarsfield ganhar do Argentino Júnior; também, como o River, ganhou seus três jogos e, dessa maneira, é um dos pontas da tabela no campeonato de abertura da primeira divisão.

Ou seja, a já ocorrida vitória do time Velez Sarsfield nos três jogos do campeonado argentino de futebol mostra-se relevante no momento presente em que se encontra o enunciador - quem, por isso, diferencia-o dos demais clubes por ser um dos líderes no campeonato. Não nos preocupando, por hora, com o caracter subjetivo e pragmático que se associa a esse uso do $\mathrm{PC}$, esse valor da forma composta pode ser mais bem esclarecido se consideramos dois traços mais objetivos de análise: o tempus e o aspecto gramatical.

Considerando primeiramente o valor temporal base de antepresente, encontramos no uso do PC uma eventualidade pretérita que é vislumbrada dentro do mesmo âmbito (MR) em que ocorre o momento da fala, haja vista que o momento de referência presente também é simultâneo ao MF. Dessa maneira, parece que no enunciado (17), a extensão temporal do "campeonato apertura de primera división" marca o momento de referência presente, isto é, o âmbito temporal de coexistência que envolve tanto as vitórias do time (ME) quanto o MF.

Por sua vez, tomando a informação proveniente do aspecto gramatical, Comrie (1976) e García Fernández (2008) afirmam que o aspecto perfeito ${ }^{28}$ marcado nesse valor volta-se ao momento que está imediatamente posterior ao tempo da situação descrita, mostrando-nos, por isso, as consequências de dada situação. Em outras palavras, a marca aspectual do perfecto compuesto traz à tona alguns estados de uma ação precedente (COMRIE, 1976). Observando esse valor aspectual no enunciado (17), parece que com o uso do PC junto ao verbo 'ganar' ('ganhar') procura-se, na verdade, salientar as consequências advindas da vitória do time, tais como se tornar líder do campeonato, ser um time de referência, entre outras.

\footnotetext{
${ }^{27}$ Enunciado retirado de uma entrevista radiofônica difundida pela rádio LV10, de Mendoza/ Argentina (23/08/2010).

${ }^{28} \mathrm{Na}$ classe aspectual de perfeito, o foco volta-se ao momento que está imediatamente posterior ao tempo da situação, mostrando-nos, por isso, os resultados da situação ou, em outras palavras, a relevância presente de uma situação concluída. É consciente desse valor que Comrie (1976) afirma que o perfeito não nos diz nada diretamente sobre a situação em si, mas relata alguns estados de uma situação precedente.
} 
Havendo comentado as informações provenientes tanto do tempus como do aspecto gramatical, torna-se mais perceptível que, tal como defendem Bybee e Dahl (1989, p. 67), o valor fundamental de relevância presente provém da observação das consequências resultantes (aspecto perfeito) de uma eventualidade pretérita, mas envolta pelo mesmo âmbito de referência presente que abarca a enunciação (tempus antepresente). Como verificaremos, a maior parte dos valores atribuídos ao PC retomará, de algum modo, o valor do tempus AP e/ou do aspecto perfeito.

Finalmente, Hernández (2013) observa que a variação entre o perfecto simple (PS) e compuesto (PC) provê ao falante um mecanismo que permite destacar um evento passado sobre outro - o qual, apesar de passado, ainda repercute de alguma maneira no momento de fala. Desse modo, para o autor, o uso do PC, em textos narrativos, permitiria diminuir a distância dos eventos descritos, de maneira que a proximidade temporal efetiva entre o enunciador e a situação descrita poder ser redimensionada e encurtada subjetivamente.

A observação de (17) permite-nos ver esse "jogo temporal" por meio do uso das duas formas do pretérito. Assim, se por um lado o PS ("costó") faz referência a uma situação mais objetivamente limitada ao momento passado em que foi concebida, com o uso do PC (ha ganado) marca-se subjetivamente uma maior proximidade entre a ação descrita e o momento de fala, posto que é nesse instante em que se observa concretamente as consequências da ação passada, isto é, encontra-se o time do Velez Sarsfield entre os líderes do campeonato de futebol.

Em síntese, Hernández (2013) observa que em algumas variedades do espanhol (San Salvador, por exemplo) a variação entre o PC e o PS permite marcar graus de proximidade e distanciamento tanto temporais quanto psicológicos entre as situações apresentadas e o enunciador. ${ }^{29}$ Segundo explica o autor, esse uso se deve a que o avanço do PC em contextos temporais (de antepresente e passado absoluto) "parece ser o produto de um recurso estilístico com consequências cognitivas notáveis que aumentam o envolvimento do enunciador no discurso", de maneira que o "PC chama a atenção para a proximidade afetiva do orador com o evento, enquanto o PS aumenta o desapego e a dissociação” (HERNÁNDEZ, 2013, p. 280).

\subsection{Resultado}

O quinto valor frequentemente atribuído à forma composta recebe o nome de resultativo, pois focaliza, no $\mathrm{MF}$, um estado que existe como consequência de um evento já ocorrido. Assim, o PC poderá expressar o resultado de um estado ou ação que lhe são anteriores, mas também poderá exprimir uma situação já ocorrida que deverá ter seus resultados presentes inferidos implicitamente. Ou seja, de qualquer maneira, com o perfecto compuesto de resultado, "descrevem-se estados que se consideram atuais ou que se comprovam na atualidade" (RAE, 2009, p. 1734). As duas possibilidades podem ser mais bem observadas pelos enunciados (18) e (19), respectivamente:

${ }^{29}$ Função que, segundo Hernández (2013, p. 280), também pode se vincular à entonação, à ordem das palavras e à morfologia. 
(18) Hay una ponderación especial hacia un personaje que es muy cuestionado después de mucho revisionismo histórico. La verdad es que no ha quedado bien parado. ${ }^{30}$

Há uma ponderação especial por um personagem que é muito questionado depois de muito revisionismo histórico. A verdade é que não está bem firme.

(19) Porque ellos consideran que han plantado bandera en el fondo del mar, entonces a partir de eso ellos pueden explorar eso $[\ldots] .^{31}$

Porque eles consideram que fixaram bandeira no fundo do mar, então por isso eles podem explorar isso.

No primeiro enunciado, o uso do PC mostra-nos o resultado presente ('no ha quedado') de uma situação originada antes do MF: o questionamento do personagem depois de revisionismo histórico. Por sua vez, em (19), notamos que a ação já terminada, expressada pela forma composta (ha plantado), implicará alguns resultados, tal como a permissão para a exploração do mar.

Rodriguez Louro (2008) afirma que esse valor tende a ser produtivo junto a predicados télicos, já que trazem marcado o ponto final da situação que descrevem. Ainda segundo a autora, o uso dos advérbios "todavia" ("ainda") e "ya" ("já") enfatizaria o valor resultativo.

A fim de avaliar como esse valor relaciona-se diretamente ao aspecto que vigora no PC, Cartagena (1999) lança mão da relação dos conceitos de tempo da situação (TS) e de tempo do foco (TF) ${ }^{32}$ e, dessa maneira, verifica que, em (20), a expressão: "en este instante" determina o TF, isto é, "aponta para o resultado da ação ocorrida no contexto do MF e não ao momento de macharse", de modo que se pode inferir que o criminoso não está no local - "ya se ha marchado".

(20) En este instante se ha marchado el sospechoso. (CARTAGENA, 1999, p. 2940)

Neste instante o suspeito foi embora.

\footnotetext{
${ }^{30}$ Enunciado retirado de uma entrevista radiofônica difundida pela rádio Palermo, de Buenos Aires/Argentina (29/09/2010).

${ }^{31}$ Enunciado retirado de uma entrevista radiofônica difundida pela rádio LV10, de Mendoza/ Argentina (13/09/2010).

${ }^{32}$ Para o autor, tempo da situação (TS) é o tempo no qual um processo designado por um verbo acontece, ao passo que tempo do foco (TF) será o período de validade de tal processo. Esses dois tempos podem se articular estabelecendo quatro relações, isto é, classes de aspecto, nas quais: (a) TF está incluído em TS; (b) TF inclui o fim de TS e o início do tempo seguinte a TS ou coincide exatamente com TS; (c) TF é posterior a TS e (d) TF é anterior a TS (CARTAGENA, 1999, p. 2940). $\mathrm{Na}$ avaliação da expressão do valor de resultado interessa-nos especialmente a relação (c).
} 
$\mathrm{O}$ valor resultativo é consequência do aspecto perfeito, pois "na leitura perfeita o complemento temporal se refere a um ponto posterior ao processo verbal designado, que é resultado ou consequência deste" (CARTAGENA, 1999, p. 2940). $O$ valor pode ser observado na figura 6 , na qual a lente representa o TF, o momento posterior ao término do evento (representado por $\mathbf{x}$ ) e quando se vislumbram as consequências provenientes dele. Notemos também que o TF envolve o MF, fazendo com que as consequências observadas sejam concomitantes ao MF.

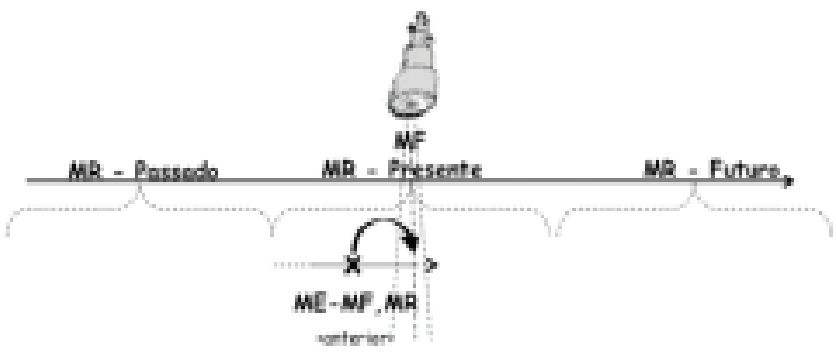

Figura 6: Do valor resultativo

\subsection{Continuidade}

Por meio do valor de continuidade, sexto sentido atribuído ao PC, descrevemos situações cuja origem é anterior a MF, mas que continuam se manifestando no presente, podendo, por suposição, seguir em direção ao futuro. Esse é o valor que se verifica em (21), no qual o estado descrito dos hospitais provém do passado e se estende em direção ao futuro.

(21) En Tucumán, los hospitales siempre han sido los portadores naturales del sistema. ${ }^{33}$ Em Tucumán, os hospitais sempre foram os portadores naturais do sistema.

Esse valor pode associar-se tanto a predicados télicos como a atélicos, expressando, por isso, eventos reiterados continuamente ou estados permanentes - como nota-se em (21). A "Nueva gramática de la lengua española" (RAE, 2009) observa que, em orações negativas, os advérbios todavialaún ('ainda') possibilitam a paráfrase "hasta el momento" ('até o momento'), de modo que muitas vezes enfatizam o valor de persistência (de uma ausência).

O contraste com o valor experiencial (AP ampliado) mostra-nos que o valor de continuidade informa o momento em que uma situação descrita inicia, bem como a reiteração dela, pelo menos, até o MF. Por sua vez, o valor de AP ampliado, por si só, não nos diz quando inicia ou termina uma situação, sabemos apenas que ocorreu em um pretérito que pode envolver, até mesmo, todo o período de vida do indivíduo. A frequência de uma situação na experiência de vida do sujeito também é uma informação aparentemente marginalizada pelo valor de

${ }^{33}$ Enunciado retirado de uma entrevista radiofônica difundida pela rádio LV7, de San Miguel de Tucumán/Argentina (30/11/2010). 
AP ampliado (experiencial), ao passo que no PC de continuidade, é um traço semântico marcado do seu início até o MF, pelo menos. Assim, na figura 7 temos as letras ( $\mathbf{x})$ expressando a reiteração da situação até o momento de fala. O uso do (x) tracejado mostra-nos a possível continuidade da situação após MF.

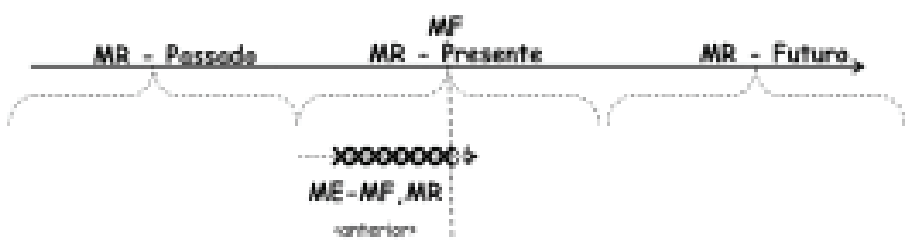

Figura 7: Do valor de continuidade

\subsection{Passado absoluto}

Os últimos valores a serem tratados são alvos de uma desatenção descritiva, o que nos proporciona um conhecimento ainda muito limitado e superficial sobre eles dentro da tradição descritiva hispânica. Esse é o caso, por exemplo, do valor tido como passado absoluto ${ }^{34}$ - sétimo sentido - que pode ser observado em enunciados como:

(22) [...] ustedes saben cuando yo me hice cargo del PAMI, hace aproximadamente un ano y medio, [...] yo he recibido el padrón de seis mil afiliados y a la fecha tenemos un padrón de ciento treinta mil afiliados. ${ }^{35}$

[...] vocês sabem que quando eu me tomei posse do PAMI, há aproximadamente um ano e meio, $[. .$.$] recebi o cadastro de cento e trinta mil afiliados e atualmente temos$ um cadastro de cento e trinta mil afiliados.

(23) Ayer he ido al cine. (ARAUJO, 2009, p. 42)

Ontem fui ao cinema.

(24) Hace tres años que se ha muerto mi padre. (TORREGO, 2002, p. 150)

Faz três anos que meu pai morreu.

Nos enunciados, as expressões "hace aproximadamente un año y medio", "ayer" e "hace tres años" mostram que a situação descrita não ocorreu dentro do âmbito primário de coexistência, mas no de anterioridade. Indicando-nos, por isso, que aparentemente o PC sofre uma mudança no que diz respeito ao tempus. Assim, analisando os exemplos sob a perspectiva reichenbachiana, teríamos

\footnotetext{
${ }^{34}$ Conforme observamos na seção III, em que discutimos a história das formas do pretérito perfecto em espanhol, considera-se esse valor como o mais inovador dentro do continuum de mudança da forma composta nas línguas românicas - havendo as línguas francesa e italiana (do norte), por exemplo, já alcançado esse estágio no uso - como também reconhece a normatização gramatical dessas línguas.

${ }^{35}$ Enunciado retirado de uma entrevista radiofônica difundida pela rádio LV7, de San Miguel de Tucumán/Argentina (30/11/2010).
} 
situações que ocorrem no âmbito de referência passada ("hace aproximadamente un año y medio", "ayer" e "hace tres años"), expressando, portanto, o valor de passado absoluto (ME,MR-MF), e não mais de antepresente (ME-MF,MR), como observamos na figura 8 .

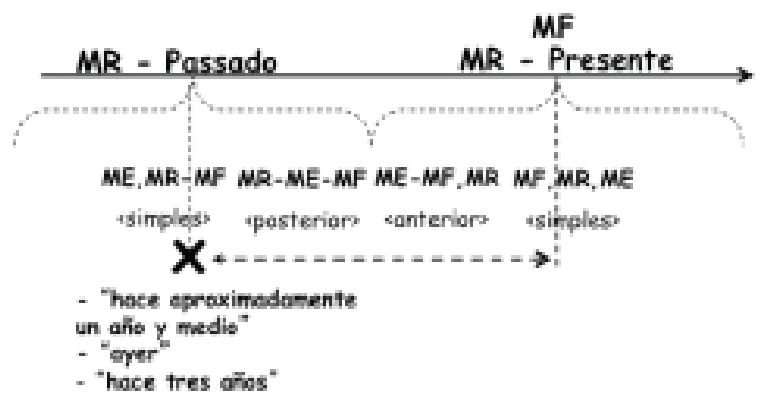

Figura 8: Do valor de passado absoluto sob a perspectiva reichenbachiana

Em resumo, a observação da categoria do tempus no uso da forma verbal com o valor de passado absoluto mostra-nos o PC aproximando-se do valor fundamental atribuído ao PS. Contudo, ainda é relevante observarmos, no enunciado (22), que há um uso do PS (hice) ocorrendo no mesmo âmbito temporal do PC (he recibido), levando-nos a pensar que há duas formas dedicadas à expressão do mesmo valor. Mas seriam essas duas formas semanticamente idênticas?

Uma resposta positiva desconsideraria, pelo menos, o traço aspectual associado, segundo Garcia Fernández (2008) e Comrie (1976), a essas formas. Isso porque o aspecto perfeito, presente na forma do $\mathrm{PC}$, faria com que se destacasse, no momento de enunciação, a relevância de uma ação concluída antes do MF - ainda que esteja em um âmbito primário de anterioridade (MR - passado). No caso do uso do PC em (22), a relevância presente pode ser verificada no resultado decorrente da comparação entre um estado passado e um estado presente, no qual a quantidade de afiliados é muito maior. Com o PS, por sua vez, a ação teria um sentido aspectual perfectivo, atendo-se, por isso, aos limites do próprio acontecimento. Observemos, na figura 9, como a relevância presente pode se dar também no uso do PC com valor de passado absoluto, isso porque o tempo de foco (lente) atem-se às consequências da situação passada no momento de fala.

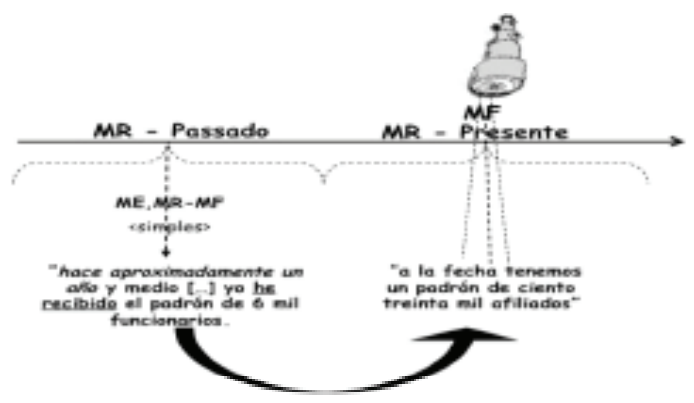

Figura 9: Do valor de passado absoluto com relevância presente 
A impossibilidade de fazer o mesmo cotejamento entre ambas as formas, em (23), leva-nos a indagar se haveria a possibilidade de o PC também compartilhar com o PS o aspecto perfectivo nesse contexto de passado absoluto. Isso também se deve à dificuldade em avaliar o que poderia ser considerado relevante no presente. Seria o caso de uma aparentemente comum ida ao cinema?

O enunciado (24) resgata a sintética análise que fazem as gramáticas da língua espanhola sobre o valor de passado absoluto com relevância presente. Segundo esses manuais, o sentido dessa oração seria justificado fundamentalmente por uma relação psicológica entre o evento e o momento da enunciação, de modo que "a morte do pai perdura de alguma forma na afetividade do falante" (TORREGO, 2002 , p.150). Segundo os gramáticos, esse valor seria justificado por um alargamento do âmbito primário de coexistência de modo a envolver fatos muito distantes, mas ainda de grande relevância psicológica para o enunciador. Assim, nada se comenta sobre a interferência do aspecto perfeito ou da possibilidade de mudança do tempus.

\subsection{Antepretérito}

A Cartagena (1999) cabe o único registro feito sobre o oitavo valor atribuído ao PC. Para o autor, o PC pode expressar antepretérito, isto é, designar algo que é objetivamente anterior a uma situação ocorrida no passado absoluto, como se vê em (25):

(25) Ese tema se ha politizado y yo que tuve que hacer en aquel momento como responsable de la obra social, poner en funcionamiento los mecanismos naturales $<T 5>$.

Esse assunto havia sido politizado e o que eu tive que fazer naquele momento, como responsável do serviço social, foi pôr em funcionamento os mecanismos naturais.

No qual, entendemos a ação "tuve" como uma referência (MR) passada em relação ao momento da fala, mas posterior ao evento "ha politizado" (ME). Tal como verificamos na notação de Reichenbach (2004), o valor ocupado agora pelo PC corresponde ao tempus passado anterior (ME-MR-MF), prototipicamente associado à forma do pluscuamperfecto de indicativo. ${ }^{36}$

Aparentemente, o uso do PC nesse contexto poderia visar, da mesma maneira que no lugar do passado absoluto, à expressão da relevância presente de um evento passado, mas que dessa vez é anterior ou antepretérito. Essa relevância é possível graças ao aspecto perfeito que vigoraria no uso do PC. Assim, no valor antepretérito, as consequências da eventualidade pretérita também são avaliadas a partir do MF, onde se fixa o tempo de foco (lente) - conforme a figura 10.

\footnotetext{
${ }^{36}$ Forma equivalente ao mais-que-perfeito do indicativo do sistema verbal da língua portuguesa.
} 


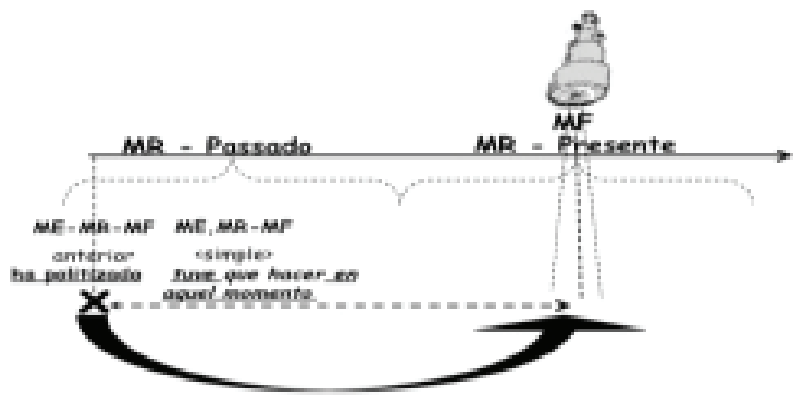

Figura 10: Do valor de antepretérito com relevância presente

\subsection{Prospectivo}

O último valor associado ao uso do PC tem o nome de prospectivo e com ele expressam-se fatos em um âmbito primário de prospectividade (de referência de futuro), como observamos em:

(26) Mañana a estas horas, ya han terminado ustedes (RAE, 2010, p. 439).

Amanhã a estas horas vocês já terão terminado.

Nesse caso, associa-se ao PC um valor de antefuturo $((0+\mathrm{V})-\mathrm{V})$ - ou futuro posterior (MF-ME-MR) sob a ótica de Reichenbach (2004). Isso se deve a que ao enunciar (26) o indivíduo deveria ter em mente que a ação ("ha terminado") é posterior ao MF, mas anterior à referência futura "mañana a estas horas" (MR). $\mathrm{O}$ uso da forma do PC, cujo valor prototipicamente associa-se a eventos anteriores à enunciação, mostra-nos, desse modo, uma maior certeza, já no momento de fala, de uma situação que ocorrerá somente no futuro.

\section{CONSIDERAÇÕES FINAIS}

Para concluirmos, conforme nos propusemos mostrar, o perfecto compuesto, na língua espanhola, é uma forma verbal eminentemente polissêmica que transita entre valores de concepção temporal, aspectual e pragmático. Desse modo, não é possível limitá-lo a expressão do valor de antepresente e de seus matizes apenas, mas há de se reconhecer que há ainda a possibilidade de lhe atribuir sentidos de ordem mais pragmático, como o de relevância presente, ou mais aspectual, como o de resultado e de continuidade, ou ainda com base mais temporal, como os sentidos de passado absoluto, antepretérito e prospectivos, que como vimos, carregam consigo marcas aspectuais e pragmáticas que permitem relacionar a situação descrita com o momento de enunciação. Em síntese, temos a oportunidade de observar que a forma do perfecto compuesto possui uma diversificada gama de sentidos, cuja compreensão tende a envolver mais do que o estudo do tempus. 
Posto que muitos elementos envolvem-se na construção de cada um dos sentidos, a análise dessa forma verbal deve considerar estruturas cotextuais (marcadores temporais, modo de ação e rede argumental do verbo, por exemplo), contextuais (fatores pragmáticos e intenção do falante) e características peculiares a cada uma das variedades da língua espanhola.

Finalmente, é importante ter em mente a heterogeneidade linguística que circunscreve a comunidade hispanófona, de tal modo que essa polissemia apresentada a partir de uma perspectiva teórico-normativa necessariamente terá sua efetiva realização alterada conforme a variedade linguística analisada do espanhol. Nessa direção, fazem-se necessários outros estudos que investigue, descreva, compare e justifique o uso que as variedades do espanhol faz da forma composta e de sua relação com o paradigma verbal do castelhano.

\section{$\overline{\text { REFERENNCIAS }}$}

ALARCOS LLORACH, E. Estudios de gramática funcional del español. Madrid: Gredos, 1980.

ALARCOS LLORACH, E. Gramática de la lengua española. Madrid: Espasa, 2005.

BELLO, A. Análisis ideológico de la conjugación castellana. Caracas: Plan Cultural, 1972.

BELLO, A. Gramática de la lengua castellana. Madrid: EDAF, 2004.

BYBEE, J. L.; DAHL, Ö.. The creation of tense and aspect systems in the languages of the word. Studies in language, v.13, n.1, pp. 51-103, 1989.

CARTAGENA, N. Los tiempos compuestos. In: BOSQUE, I.; DEMONTE, V. Gramática descriptiva de la lengua española. Madrid: Espasa, 1999. 2 v. pp. 2933-2975.

COMRIE, B. Aspect. Cambridge: Cambridge University Press, 1976.

DAHL, Ö.; HEDIN, E. Current Relevance and Event Reference. In: DAHL, Ö. (ed.). Tense and aspect in the languages of Europe. Berlin: de Gruyter, 2000. pp. 385-402.

GARCÍA DE DIEGO, V. Gramática histórica española. Madrid: Gredos, 1951.

GARCÍA FERNÁNDEZ, L. El aspecto gramatical en la conjugación. Madrid: Arco Libros, 2008.

GILI GAYA, S. Curso superior de sintaxis española. 9 ed. Barcelona: Biblograf, 1970.

HERNÁNDEZ, J. E.. Focus on speaker subjective involvement in Present Perfect grammaticalization: Evidence from two Spanish varieties. Borealis: An International Journal of Hispanic Linguistics, Tromsø, 2013, v. 2, n. 2. pp. 261-284, 2013.

GUTIÉRREZ ARAUS, M. L. Formas temporales del pasado de indicativo. 2 ed. Madrid: Arco Libros, 1997.

GUTIÉRREZ ARAUS, M. L. Caracterización de las funciones del pretérito perfecto en el español de América. In: CONGRESO INTERNACIONAL DE LA LENGUA ESPAÑOLA, $2^{\circ}, 2001$, Valladolid. Paneles y ponencias del II Congreso Internacional de la Lengua Española. Madrid: Centro Virtual Cervantes, 2001. 
HERNÁNDEZ ALONSO, C. Gramática funcional del español. 3 ed. Madrid: Gredos, 1996.

KANY, C. E. Sintaxis hispanoamericana. Trad. Martín Blanco Álvarez. Madrid: Gredos, 1970.

KOVACCI, O. El comentario gramatical: teoría y práctica. Madrid: Arco Libros, 1992. 2 v.

LENZ, R. La oración y sus partes. Madrid: Centro de Estudios Históricos, 1920.

NEBRIJA, A. Gramática de la lengua castellana. Edicion de Antonio Quilis. Madrid: Editora Nacional, 1980.

PORTO DAPENA, J. A. Tiempos y formas no personales del verbo. Madrid: Arco Libros, 1989.

QUESADA PACHECO, M. Á. El sistema verbal del español de América: de la temporalidad a la espectualidad. Español Actual, Madrid, n. 75, pp. 5-26, 2001.

RAE. Esbozo de una nueva gramática de la lengua española. Madrid: Espasa, 1986.

RAE. Nueva gramática de la lengua española: Morfología y Sintaxis I. Madrid: Espasa, 2009.

RAE. Manual de la nueva gramática de la lengua española. Madrid: Espasa, 2010.

REICHENBACH, H. The tenses of verbs. In: STEVEN, D.; GILLON, B. S. (Orgs.). Semantics: a reader. New York: Oxford University Press, 2004. pp. 526-533.

RODRÍGUEZ LOURO, C.. Usos del Presente Perfecto y el Pretérito en el español rioplatense argentino. In: CONGRESO INTERNACIONAL DE ALFAL, 15, 2008, Montevideo. Actas del XV Congreso Internacional de ALFAL. Montevideo: Alfal, 2008.

ROJO, G. La temporalidad verbal en español. Verba: Anuário Gallego de Filología, Santiago de Compostela, v. 1, pp. 69-149, 1974.

ROJO, G. Relaciones entre temporalidad y aspecto en el verbo español. In: BOSQUE, I. (Org.). Tiempo y aspecto en español. Madrid: Cátedra, 1990. pp. 17-43.

ROJO, G; VEIGA, A. El tiempo verbal: los tiempos simples. In: BOSQUE, I.; DEMONTE, V. Gramática descriptiva de la lengua española. Madrid: Espasa, 1999. 2 v. pp. 2867-2934.

SANTOS, A. J. O tempo e o aspecto verbal no indicativo em português, Littera, São Luis, n.10, pp. 55-74, 1974.

SPERBER, D.; WILSON, D. Outline of Relevance Theory. LinksLetters, n. 1, pp. 35-56, 1994.

SPERBER, D.; WILSON, D. Relevance: Communication and Cognition. 2 Ed. Oxford: Blackwell, 1999. 